\title{
Disappearing African Crocodiles
}

\author{
A.C. Pooley
}

Dwarf crocodile Osteo/aemus tetraspis

In the last thirty years at least three million crocodiles have been killed in Africa for their skins - and the figure may be much higher. As a result the Nile crocodile has declined seriously almost everywhere, and hunters are now turning to other species, none of which are anywhere abundant, to supply the trade. Only Zimbabwe has established viable crocodile farms, but even these were able to cull only 2253 animals for hides in the three years 1978-80.

One of the first tasks of the IUCN/SSC Crocodile Specialists' Group (CSG), formed in 1969 under the chairmanship of Dr Hugh Cott, was to conduct a questionnaire survey of the current status of the African species.*

In 1980 an attempt was made to gather new data, and another questionnaire was mailed to field biologists and universities, and to conservation, fisheries, customs and excise and forestry departments. The replies revealed a reluctance in many countries to divulge information on the number of hides exported annually. Quite obviously some government departments earn considerable revenue from export and licence fees, and some are embarrassed at having to admit that there has been a dramatic decline in crocodile populations and that little or no effort had been made to curb this over-exploitation. The results were reported at the CSG meeting in Gainesville, Florida, in August 1980.

Unfortunately, from the statistics available we have no idea which crocodile species are being or have been exploited for the hide trade. Reports indicate that the Nile crocodile $C$. niloticus has suffered a tremendous decline over much of its range, and also that hunters and tanners are now turning to the long snouted crocodile $C$. cataphractus, the West African dwarf crocodile Osteolaemus tetraspis and the Congo dwarf crocodile $O$. osborni. These three species are nowhere really abundant; moreover, very little is known of their biology or ecology, and we only have limited data on their distribution. We would very much appreciate hearing from anyone with field experience of these species. Data on export figures would also be welcome.

The Table lists all available figures on numbers of hides exported. From some countries we have figures or weights of skins, or their value in various currencies, but these cannot be converted to numbers of animals involved. In addition hides have been exported from countries where no records are available: Angola, Benin, Burundi, Cameroon, Central African Republic, Gambia, Ghana, Ivory Coast, Mali, Malagasy Republic, Mozambique, Niger,

* Published in Crocodiles, IUCN Publications New Series, Suppl. Paper no. 33: 1-98, 1972. 


\section{Export of Crocodile Hides from African Countries}

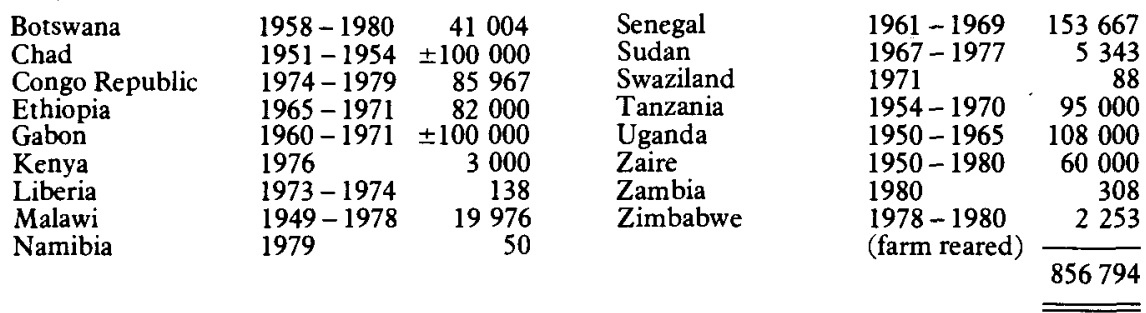

Nigeria, Rwanda, Sierra Leone, Somalia, South Africa, Togo, Upper Volta. In most of these countries there has been extensive over-exploitation. An educated guess, based on weights and the monetary value of skins and the available figures, plus the opinions of over a hundred biologists and conservationists, is that, between 1950 and 1980 , at least three million crocodiles have been slaughtered in Africa for their skins. And the figure may be much higher.

In reply to the question 'What is the current status of crocodile populations in your country?' most replies said endangered, very rare, scarce, seriously depleted, seldom seen or uncommon. Very few countries could report: safe, satisfactory, or out of danger. Whether specifically stated or implied, most correspondents agreed that populations could only be restored by stringent conservation measures.

In addition to killing for belly hides, the survey revealed other causes for the decline in crocodile populations. These were (not necessarily in order of importance):

1. Killing by fishermen due to the increasing and widespread use of gill nets;

2. Hunting for the flesh and the eggs, eaten by certain tribal peoples; hunting also for the supposed medicinal properties of organs such as the heart, liver, brain and fat;

3. Trapping by tribal peoples because crocodiles may consititue a threat to humans and livestock, cause damage to fish nets and are thought to cause a decline in fish populations;

4. Exporting for zoological parks and animal dealers;

5. Killing for rewards in countries where crocodiles are classed as dangerous predators, or vermin, because crocodiles are not protected, or because the demand for skins and the price offered is so high that it is hard to deter men from defying the regulations.

6. Habitat loss due to reclamation of swamps for sugar and rice crops; expansion of forestry; destruction of riverine forest for subsistence crops; burning of reedbeds and nest trampling by cattle. The general availability of arms and ammunition due to wars and the collapse of controls has in some countries speeded up the extermination of wildlife, including crocodiles.

\section{Crocodile Farming}

There have been several claims that crocodile farms in Africa are now supplying sufficient quantities of hides to meet the requirements of the leather industry. In fact only Zimbabwe has made any real progress in farming/rearing techniques, and from the four operational projects a total of 2253 animals were culled for hides over a period 1978-80. Zimbabwe has also made great strides in captive breeding. In 1979, 87 captive females at two farms produced 1906 eggs, 
and a third farm has set aside 30 captive females for breeding. In several other countries there are individuals considering establishing crocodile farms for commercial production, including Ivory Coast, Zambia, Mozambique and South Africa. But they are likely to produce only a fraction of the hides needed annually by the large tanneries.

Zimbabwe farmers operate on a system that requires them to return a small percentage of live animals back to the wild. In Natal we have restocked local waterways with over 1000 live young - some of these animals will go to Swaziland and Mozambique. But these numbers are only a drop in the ocean, and the future is not bright. African crocodiles are rapidly disappearing as an observable part of the fauna in some 36 countries.

A.C. Pooley, Natal Parks, Game and Fish Preservation Board, Natal, S.Africa.

Note: The belief that crocodiles reduce the number of fish is widely held (page 39 , Note 3 ). $\mathrm{Mr}$ Pooley writes: there is no published scientific data to prove that crocodiles are detrimental to commercial fisheries enterprises. In our waterways crocodiles are the only predators of the large, less palatable, predatory fish, maintaining an important balance in species diversity. By fertilising the waters with the remains of their prey, they also speed up nutrient recycling by providing minerals and phosphates to support the rich aquatic fauna and flora.

\section{Increasing the Gharials}

Between May 1979 and March 1980, 179 captive-bred gharials Gavialis gangeticus were released in two Indian sanctuaries, the Katermaghat, near the Indo-Nepalese border in Bahraich, and the Chambal in the three states of Uttar and Madhya Pradesh and Rajasthan. The gharials had been hatched under the Crocodile Rehabilitation Scheme in two centres, Kukrail near Lucknow and Hatermiaghat, from eggs collected in the wild, and were kept in captivity until they reached $1 \frac{1}{2}$ metres, when they are considered to be safe from predators. Hatching success is between 80 and 90 per cent; in the wild destruction of eggs and young is believed to be up to 95 per cent.

\section{Sea Turtles and Shrimp Trawls}

In US waters the 'by-catch' in shrimp- trawls (the fish and other marine life caught accidentally, and thrown back into the sea) may be as high as one billion pounds in weight a year, and includes sea turtles, of which all species are endangered. In 1980 2000 dead sea turtles were washed up on the south-eastern US coast. But the National Marine Fisheries Service has now developed a trawl-net modification that should keep out the turtles and a large proportion of all the other wasted fish and marine life. The SSC has written to President Reagan urging that it be widely used, and has asked FAO to disseminate the information.

\section{Freshwater Turtles and Tortoises: the Threats}

According to the newly formed SSC Freshwater Chelonian Group, 37 of the 180 freshwater turtle and tortoise species (about 20 per cent) are threatened to some degree. Habitat destruction is increasingly a cause for this, due to dams on rivers, which may block migration routes and inundate nest sites, and the draining of ponds and wetlands. Even deforestation has serious effects, causing waterways to silt up; the subsequent floods may destroy all one year's nests, as has happened in the Sunderbans in India and on the Perak river in Malaysia. Surprisingly pollution of rivers does not seem to be a major problem; many turtles and tortoises thrive in polluted conditions. 